\title{
ANÁLISE DO REJEITO DE CERÂMICA VERMELHA E SUA APLICAÇÃO COMO FONTE DE POTÁSSIO NA AGRICULTURA
}

\author{
L. L. S. Nobre', F. S. D. Araújo', A. P. A. Dantas', J. Y. P. Leite ${ }^{1}$ \\ 'Laboratório de Processamento Mineral - Instituto Federal de Educação Ciência e Tecnologia do RN \\ lanalopesrn@hotmail.com - paduadantas@gmail.com-franciolliaraujo@gmail.com - jyp.leite@ifrn.edu.br
}

Artigo submetido em outubro/2011 e aceito em dezembro/2011

\section{RESUMO}

A indústria de cerâmica vermelha é importante na composição da economia do Rio Grande do Norte, em particular pela sua empregabilidade. A produção de telha é responsável por cerca de 60,0\% dos artefatos cerâmicos, com mais de 50 milhões de peças fabricadas por mês. O baixo nível tecnológico leva a geração de cerca de $20,0 \%$ de rejeito das peças produzidas, equivalendo a valores da ordem de 10 milhões de peças. Estas são dispostas inadequadamente no meio ambiente. Estes rejeitos foram amostrados e caracterizados, identificando em média de $4 \%$ de óxido de potássio em sua composição. Este trabalho analisa o potencial do rejeito da cerâmica estrutural como fonte de potássio, das quais foram coletadas amostras submetidas a processo de moagem em moinho de martelos, seguida de análise granulométrica, química e mineralógica. Foram realizados estudos de extração de potássio utilizando ácidos orgânicos (cítrico e oxálico) na concentração de $0,01 \mathrm{~mol}^{-1} \mathrm{I}^{-1}$. O trabalho foi realizado em incubadora Shaker sob agitação de $150 \mathrm{rpm}$, temperatura de $30^{\circ} \mathrm{C}$ e tempo de contato de $24 \mathrm{~h}$.

PALAVRAS-CHAVE: rejeito de cerâmica, cerâmica estrutural, fertilizantes agrícolas, liberação do potássio.

\section{RED CERAMIC TAILINGS ANALYZES AND YOUR APLICATION AS POTASH SOURCE TO AGRICULTURE}

\section{ABSTRACT}

The red ceramic industry is very important to Rio Grande do Norte economy, particularly by its employability. The roof cover production is responsible for almost $60.0 \%$ of ceramic artifacts with more than 50 million pieces produced per month. The rudimentary production generates about $20.0 \%$ of tailings, almost 10 million pieces. These tailings were sampled and characterized identifying about $4.0 \%$ of potash oxide in your composition. This paper analyses the potential of this tailings as potash source for agriculture purposes. Samples were collected, submitted to grinding at hammer mill, size determinate by sieving, chemical and mineralogical analyzes by XRD and XRF. Studies of potash extraction were conducted using organic acids (citric and oxalic) at concentrations of $0.01 \mathrm{~mol}^{-1} \mathrm{I}^{-1}$ in Shaker incubator under $150 \mathrm{rpm}$ agitation, 30 Co and contact time of 24 hours.

KEY-WORDS: ceramic tailing, structural ceramic, agriculture fertilizing, potash liberation 


\section{ANÁLISE DO REJEITO DE CERÂMICA VERMELHA E SUA APLICAÇÃO COMO FONTE DE POTÁSSIO NA AGRICULTURA}

\section{INTRODUÇÃO}

A indústria de cerâmica é importante para a economia do Rio Grande do Norte. Pesquisa realizada pelo FIERN/SENAI em 2001 mostrou que existiam cerca de 206 empresas no Estado, no entanto somente 159 estavam em operação (Melo, M. M., 2006). O trabalho mostrou que cerca de até $20 \%$ da produção era perdida por problemas no processamento, o que gerava em torno de 10 milhões de peças transformadas em rejeito. Estes resíduos são dispostos de maneira inadequada no meio ambiente.

Com o objetivo de estudar uma rota tecnológica de valoração do rejeito de cerâmica estrutural este rejeito foi objeto de trabalho de caracterização dada à indicação de potássio em sua composição.

O Brasil é um dos poucos países do mundo com enorme potencial para ampliar a sua produção agrícola, seja pelo aumento de produtividade, seja pela expansão da área plantada. Com isto estará contribuindo, não somente para uma maior oferta de alimentos no contexto mundial, mas também para atender a crescente demanda interna de sua população. O Governo Federal está estimulando a busca de alternativas de rotas para a produção de potássio. $\mathrm{Na}$ área mineral são pesquisados as rochas e minerais portadores de potássio que possam ser usados como fonte alternativa, em complementação ao uso dos fertilizantes convencionais.

No país são encontradas reservas de minerais primários com teores elevados de $\mathrm{K}$, entretanto a maior parte possui o $\mathrm{K}$ na estrutura de difícil solubilização ou pouco solúvel, o que dificulta a sua disponibilidade para as plantas, o que ocorre, por exemplo, com os silicatos (Martins et al., 2008).

O potássio (K) é um dos macronutrientes mais utilizados pelas plantas, ficando atrás apenas do nitrogênio e fósforo. É matéria-prima indispensável ao desenvolvimento das plantas e sua forma solúvel é facilmente lixiviada pelo solo. É o elemento ativador de muitas enzimas, atua na fotossíntese e na síntese de proteínas (Filho, 2008).

Cerca de $94 \%$ do $\mathrm{K}$ produzido no mundo é utilizado na forma de sais como fertilizante. Os $6 \%$ restantes são empregados na confecção de vidros especiais, sabão e detergentes (IBRAM, 2010). No uso agrícola, $90 \%$ encontram-se na forma de cloreto de potássio, seguido por sulfato de potássio, com menos de $5 \%$. O restante compreende sulfato duplo de magnésio e potássio e nitrato de potássio (Oliveira \& Souza, 2007).

O potássio é um recurso natural não-renovável, sendo assim é preciso estudar formas de uso mais eficiente, fontes alternativas, técnicas que permitam sua extração do sistema, bem como o uso no plantio direto.

A extração de potássio é efetuada com a utilização de ácidos orgânicos de baixo peso molecular, como oxálico, cítrico, lático, succínico, dentre outros. Estes agem por meio da formação de complexos ácidos orgânicos-metal, trocas de ligantes e reações de protonação (Simardet al., 1992). As soluções diluídas destes ácidos, normalmente em tempos crescentes de equilíbrio com a amostra, têm sido utilizadas em estudos de cinética de liberação da reserva de K e Mg (Song \& Huang, 1998).

Os argilominerais são fontes primárias para a produção de cerâmica estrutural e estes em suas composições têm minerais portadores de potássio, consequentemente os rejeitos da fabricação de artefatos cerâmicos são materiais com potencial para investigação de extração de potássio. A Figura 1 mostra a disposição inadequada de rejeito de telha em empresas do ramo na região Seridó, Estado do Rio Grande do Norte. 


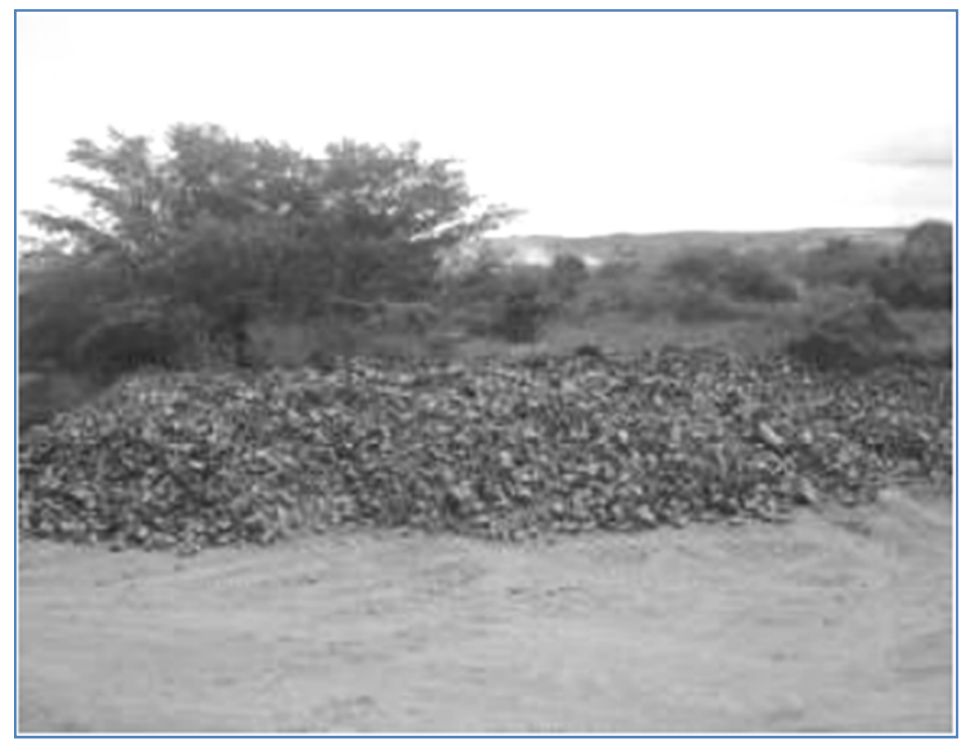

Figura 1 - Rejeito de telha - Região Seridó/RN.

\section{MATERIAIS E MÉTODOS}

\section{Rejeito de Telha}

A amostra estudada é um rejeito de telha proveniente de uma empresa cerâmica localizada no município de Parelhas, Rio Grande do Norte, a qual foi submetida à moagem em moinho de martelos com corte em $2 \mathrm{~mm}$. A massa utilizada foi de $5 \mathrm{Kg}$.

\section{Caracterização química e mineralógica}

A composição química foi determinada utilizando um FRX 720 fabricado pela Shimadzu e a composição mineralógica foi realizada usando técnica de difração de raios $X$ com o equipamento EDX 7000 da Shimadzu.

\section{Ensaios de Extração de Potássio}

As soluções extratoras têm a função de reproduzir o ambiente do solo durante a assimilação dos nutrientes pelas raízes das plantas. Plantas e microrganismos podem promover direta ou indiretamente, alterações físicas,químicas e biológicas na rizosfera (microregião entre a raiz e o solo).Na realização deste trabalho foram usadas as soluções apresentadas na tabela 1.

\section{Tabela 1 - Soluções extratoras utilizadas na liberação do K}

\begin{tabular}{c|c}
\hline Solução Extratora & Concentração $(\mathrm{mol} / \mathrm{l})$ \\
\hline Ácido Cítrico $\left(\mathrm{C}_{6} \mathrm{H}_{8} \mathrm{O}_{7}\right)$ & 0,01 \\
\hline Ácido Oxálico $\left(\mathrm{C}_{2} \mathrm{H}_{2} \mathrm{O}_{4} \cdot 2 \mathrm{H}_{2} \mathrm{O}\right)$ & 0,01 \\
\hline
\end{tabular}

O processo de extração foi realizado utilizando erlenmeyers, nos quais foram adicionados $50 \mathrm{~mL}$ de solução extratora e 5,0g de amostra do rejeito de telha. Os recipientes foram mantidos sob agitação de $300 \mathrm{rpm}$, em incubadora Shaker, a temperatura ambiente por um período de 24horas(Metodologia sugerida por Silva(2009)) e 48h. A figura 2 apresenta o equipamento. 


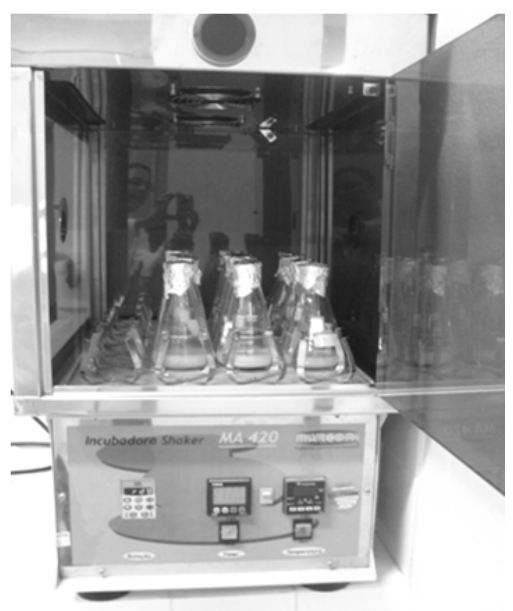

Figura 2. Experimento de extração de potássio

As amostras que passaram pelo processo de extração, após o tempo de contato, foram filtradas, secadas em estufa e submetidas a técnica de espectroscopia de fluorescência de raios-X.

\section{RESULTADOS E DISCUSSÕES}

\section{Caracterização do rejeito de telha}

A composição química determinada por espectroscopia de fluorescência de raios- $X$ é apresentada na tabela 2.

Tabela 2- Composição química do rejeito de telha estudado

\begin{tabular}{|c|c|}
\hline Elementos & \% \\
\hline $\mathrm{SiO}_{2}$ & 47,46 \\
\hline $\mathrm{Al}_{2} \mathrm{O}_{3}$ & 23,04 \\
\hline $\mathrm{Fe}_{2} \mathrm{O}_{3}$ & 17,72 \\
\hline $\mathrm{K}_{2} \mathrm{O}$ & 3,80 \\
\hline $\mathrm{MgO}$ & 3,13 \\
\hline $\mathrm{CaO}$ & 2,36 \\
\hline $\mathrm{TiO}_{2}$ & 1,74 \\
\hline $\mathrm{MnO}$ & 0,21 \\
\hline $\mathrm{P}_{2} \mathrm{O}_{5}$ & 0,13 \\
\hline Perda ao Fogo & 0,08 \\
\hline Total & 99.59 \\
\hline
\end{tabular}

Os valores de $\mathrm{SiO}_{2}$ e $\mathrm{Al}_{2} \mathrm{O}_{3}$ correspondem a mais de $70 \%$ do total dos compostos apresentados, sendo o $\mathrm{SiO}_{2}$ em maior quantidade. Nota-se que, em termos de nutrientes, a amostra apresenta 3,80\% de $\mathrm{K}_{2} \mathrm{O}$, provavelmente devido à presença da muscovita e da biotita. Entretanto, não se pode afirmar que esse é o teor de potássio disponível no mineral, pois essa disponibilidade depende da capacidade de troca iônica e condições químicas para a sua extração. 
A figura 2(a) mostra uma distribuição qualitativa das fases minerais quartzo, albita, muscovita, anortita e biotita, confirmado pelo resultado da análise química. A figura 2(b) apresenta a fotomicrografia do rejeito mostrando sua microestrutura.

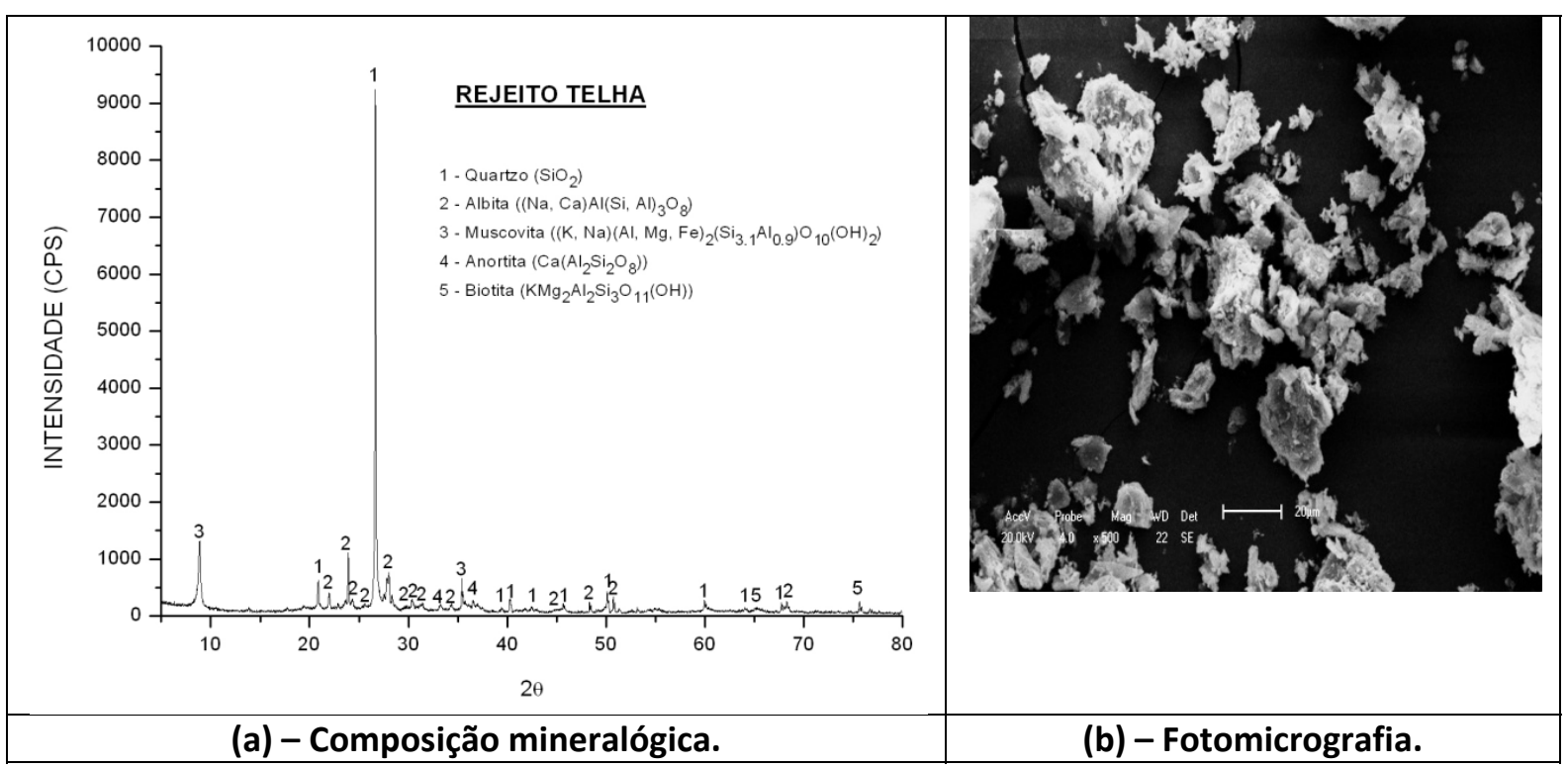

Figura 2 - Composição mineralógica e micrografia dos rejeito de telha.

\section{Ensaios de liberação de potássio}

As Figuras 3 e 4 mostram os resultados de liberação de potássio do rejeito de telha em soluções de ácido cítrico $0,01 \mathrm{~mol} / \mathrm{l}$ e oxálico $0,01 \mathrm{~mol} / \mathrm{l}$. As faixas granulométricas utilizadas foram $9 \#, 100 \#$ e $200 \#$ e os tempos de extração de 24 e 48 horas, respectivamente. A composição química do rejeito de telha indica que a amostra contém $3,80 \%$ de óxido de potássio. Nos experimentos foram utilizadas amostras de rejeito de telha com massa de $5 \mathrm{~g}$ das quais $190 \mathrm{mg}$ são de íons de $\mathrm{K}$.

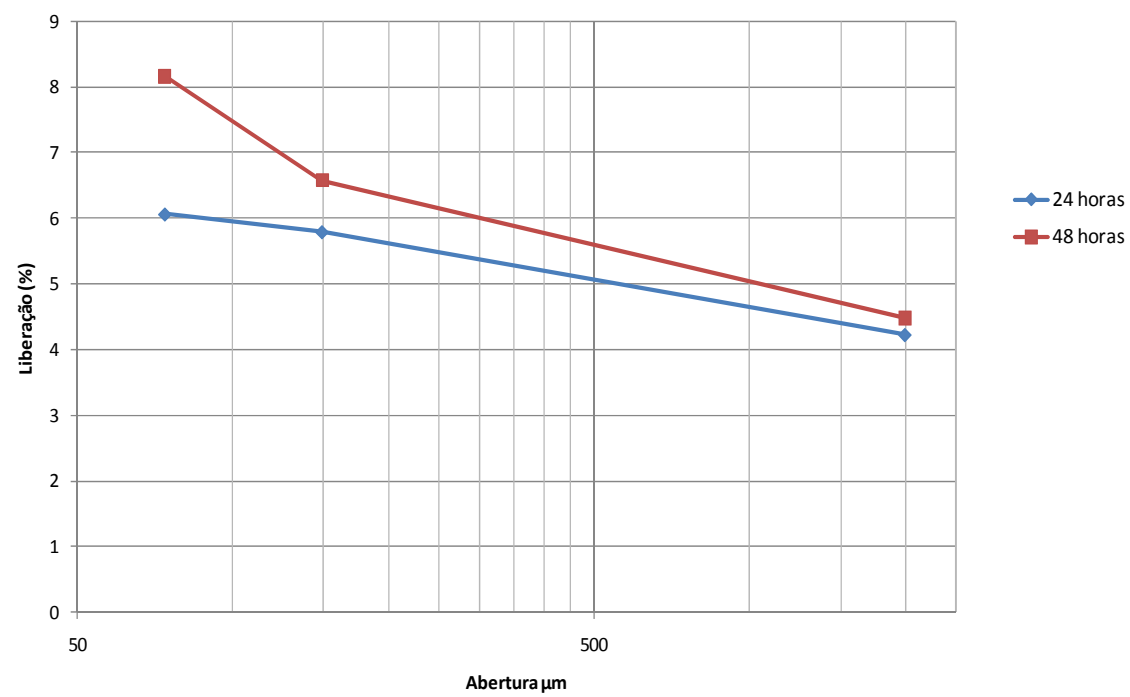

Figura 3 - Representação da liberação de K na solução extratora de ácido oxálico

Analisando a figura 2-a é possível verificar que o $\mathrm{K}$ presente no rejeito de telha encontra-se na muscovita e biotita, ou seja, nos minerais micáceos. Com isso, os íons de $\mathrm{K}$ mais disponíveis para troca 
iônica seriam os superficiais enquanto que os interlamelares são de mais difícil acesso. 0 ácido oxálico agiu promovendo uma solubilidade forçada, permitindo que os íons mais internos fossem alcançados.

A redução da granulometria eleva a superfície de contato, o que favorece a liberação do potássio levando a um melhor resultado de extração a granulometria de $200 \#$ com tempo de contato de $48 \mathrm{~h}$ (8,16\%).

A Figura 4 apresenta a liberação de potássio para a solução extratora de ácido cítrico.

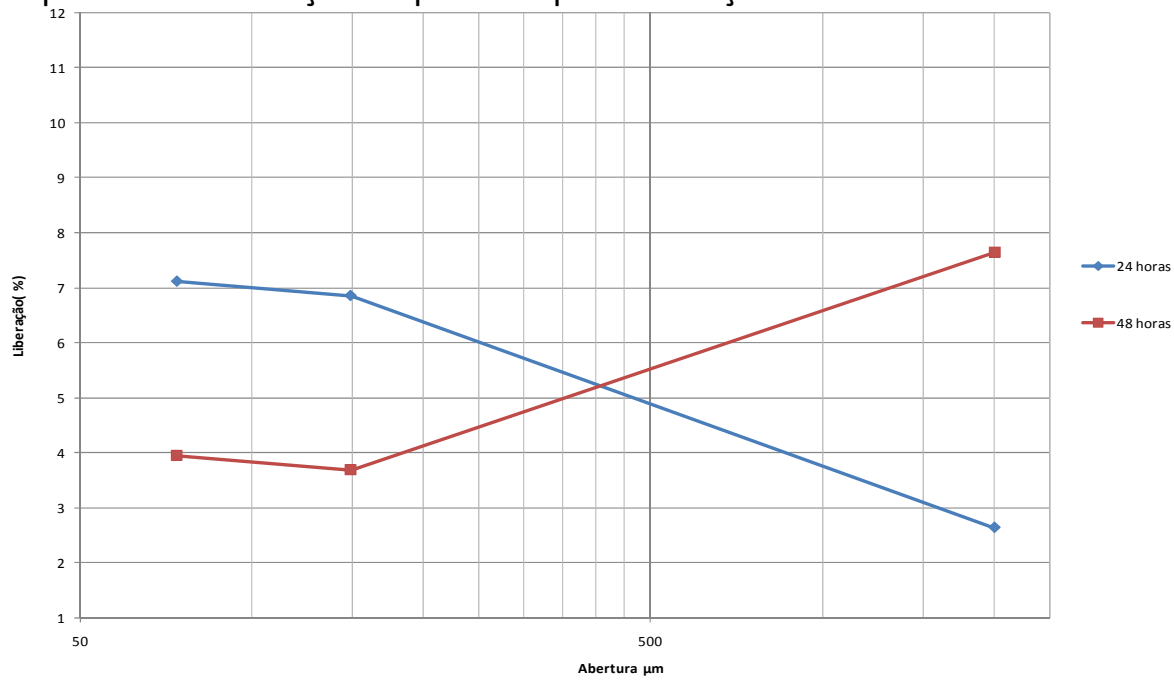

Figura 4 - Representação da liberação de K na solução extratora de ácido cítrico

Analisando a figura 4 é possível verificar que no intervalo de tempo de $24 \mathrm{~h}$ o ácido cítrico atuou de maneira idêntica ao oxálico, ou seja, o ácido promove a solubilização das espécies que contem o mineral $\mathrm{K}$ interlamelar.

No segundo intervalo de tempo (48h), observou-se uma inversão de resultados, provavelmente, o ácido cítrico atuou mais fortemente no $\mathrm{K}$ superficial presente na faixa granulométrica $9 \#$ mais disponíveis para troca iônica por estarem em sítios mais acessíveis ao extrator.

Quando se reduziu a granulometria para 100\# e 200\#, apesar da elevação da área superficial o teor de potássio extraído foi reduzido de modo significativo. Esse resultado pode estar associado a ação da solução de ácido cítrico que avançou em direção ao centro das partículas, onde o $\mathrm{K}$ está mais fortemente retido não provocando a solubilização necessária causando uma queda na liberação desse íon. O melhor resultado de extração foi verificado na granulometria de $9 \#$ com tempo de contato de $48 \mathrm{~h}(7,64 \%)$, ou seja, dos 3,8\% de potássio disponível na amostra, 7,64\% foi extraído.

\section{CONCLUSÕES}

Os rejeitos da indústria cerâmica estrutural do Estado do Rio Grande do Norte podem ser fonte potencial de potássio para a agricultura, onde os resultados deste trabalho apresentam indicadores importantes para a sua valoração e minimização do impacto ambiental.

É observado que a fonte de potássio esta associada aos argilominerais e aos minerais micáceos. Estas fontes de íons de potássio mais disponíveis para troca iônica estão nas áreas superficiais, enquanto que os vazios interlamelares são de mais difícil acesso.

O ácido oxálico removeu $8,16 \%$ de potássio para o tempo de contato de $48 \mathrm{~h}$, provavelmente por ter promovido uma solubilização forçada das espécies que contém o mineral $\mathrm{K}$, permitindo que os íons mais internos fossem alcançados. A redução da granulometria e a elevação do tempo de contato favoreceram a eficiência do processo.

$\mathrm{O}$ ácido cítrico atuou de maneira idêntica ao oxálico nas primeiras $24 \mathrm{~h}$. No segundo intervalo de tempo (48h) ao diminuir a granulometria do rejeito de telha para $100 \#$ e $200 \#$, o teor de $\mathrm{K}$ extraído 
diminuiu de modo significativo. Pode-se considerar que ao decorrer da extração a ação da solução de ácido cítrico avançou em direção ao centro das partículas, onde o $\mathrm{K}$ está mais fortemente retido não provocando a solubilização necessária causando uma queda na liberação desse íon. O melhor resultado de extração foi verificado na granulometria de 9 \# com tempo de contato de $48 \mathrm{~h}(7,64 \%)$.

Os resultados obtidos neste trabalho mostram que o rejeito de cerâmica estrutural é uma fonte potencial para extração de potássio para uso na agricultura, sendo assim é recomendável avançar nos trabalhos visando definir rotas de processo e a quantificação desta matéria prima como fonte de potássio para a agricultura.

\section{AGRADECIMENTOS}

Os autores do trabalho expressam os agradecimentos ao CNPq - FINEP, FAPERN (Projeto Fortalecimento da Estrutura de Apoio a Pesquisa para APL mineral do Rio Grande do Norte) pelo financiamento deste trabalho.

\section{REFERÊNCIAS BIBLIOGRÁFICAS}

1. Melo, M. M. Formulação e Caracterização de massas de grés porcelanato preparados a partir de matérias primas naturais do Rio grande do Norte e com adição de chamotedetelha. Dissertação de Mestrado, UFRN, 177p, 2006

2. Silva, A. S. S. Caracterização de flogopitito da Bahia como fertilizante alternativo de potássio. Dissertação de Mestrado, IQ/ UFRJ, 72p, 2009

3. Embrapa - Rochas moídas como fonte de potássio para o milho em solo de serrado - Boletim de pesquisa e desenvolvimento, Abril, 2006

4. Song, S. K \& Huang, P. M. Dynamicsos potassium release from potassium bearing minerals as influenced by oxalic and citric acids. SoilSci Soc. Am. J, 52: 383-390, 1988.

5. França. S. C. A. Estudo da aplicação de resíduos de vermiculita como fertilizante alternativo de potássio, Anais do Segundo Simpósio de Minerais Industriais do Nordeste, p 125 - 131

6. Melo, V.F., et al.; Cinética De Liberação De Potássio E Magnésio Pelos Minerais Da Fração Argila De Solosdo Triângulo Mineiro. R. Bras. Ci. Solo, 29:533-545, 2005.

7. Sparks, D.L. and Carski, T.H., 1985. Kinetics of Potassium Exchange in Heterogeneous Systems. Appl. Clay Sci., 1: 89--101.

8. Martins, E.S.; Oliveira, C.G.; Resende, A.V.; Matos, M.S.F. Rochas Silicáticas como Fontes Minerais Alternativas de Potássio para a Agricultura. In: Luz, A.B.; Lins, F.F. (EE.) Rochas e Minerais Industriais: Usos e especificações. 2 ed. Rio de Janeiro: CETEM 2008. p. 209.

9. SOUZA, D.M.G., MIRANDA, L.N. e OLIVEIRA, S.A., Acidez do solo e a sua correção. In: Fertilidade do Solo, Novais, R.S. et al (Eds), 1ạedição, Viçosa, Minas Gerais, 2007, p.205-274. 